\title{
ALFABETIZAÇÃO CIENTÍFICO-TECNOLÓGICA E CULTURA INDÍGENA NA FORMAÇÃO INICIAL DE PROFESSORES EM EDUCAÇÃO DO CAMPO - CIÊNCIAS DA NATUREZA
}

\author{
Scientific-Technological Literacy and Indigenous Culture in the Initial Training of \\ Teachers in Rural Education - Sciences of Nature
}

\author{
Moises Marques Prsybyciem ${ }^{1}$ \\ Almir Paulo dos Santos ${ }^{2}$
}

\begin{abstract}
Resumo: Este artigo tem o objetivo de analisar as contribuições do desenvolvimento de um componente curricular para a promoção de uma Alfabetização Científico-Tecnológica (ACT) e sua articulação com a cultura indígena Kaingang na formação inicial de professores em Educação do Campo - Ciências da Natureza de uma universidade federal brasileira. A abordagem metodológica da pesquisa é qualitativa e, no que refere aos procedimentos técnicos, é delineada como pesquisa-ação. Participaram do estudo 23 acadêmicos. Desse total, vinte são oriundos de terras indígenas da cultura Kaingang e três vêm de um contexto de agricultura familiar. Para coleta/construção dos dados, foram utilizados questionário, roteiro de observação e produção escrita dos acadêmicos (propostas didáticas). Os principais resultados da investigação apontam a preocupação com a construção de uma ACT mais politizada, que estimule uma leitura crítica e consciente de mundo, e uma maior participação social em processos de tomada de decisão sobre Ciência-Tecnologia. Esse processo pode ser alcançado pela superação da concepção tradicional de educação, por meio das discussões das interrelações Ciência-Tecnologia-Sociedade (CTS), de uma formação para ação social e de uma educação científica mais comprometida, inclusiva e democrática. Tais resultados contribuem para estimular a construção de uma ACT nessa perspectiva e sua relação com a cultura e os saberes tradicionais indígenas na formação inicial de professores em Educação do Campo.
\end{abstract}

Palavras-chave: Formação Inicial de Professores. Cultura Indígena Kaingang. ACT. Educação do Campo. Ciências da Natureza.

\begin{abstract}
This article aims to analyze the contributions of the development of a curricular component for the promotion of Scientific-Technological Literacy (STL) and its articulation with the Kaingang indigenous culture in the initial teacher training in Rural Education - Natural Sciences at a Brazilian federal university. The research methodological approach is qualitative and concerning the technical procedures, it is outlined as an action research. Twenty-three academics participated in the study. From this total, twenty are from indigenous lands of the

\footnotetext{
${ }^{1}$ Graduação em Licenciatura em Química pela Universidade Estadual de Ponta Grossa (2010), Mestrado em Ensino de Ciência e Tecnologia (2015) pela Universidade Tecnológica Federal do Paraná (UTFPR) e doutorando do Programa de Pós-Graduação em Ensino de Ciência e Tecnologia pela UTFPR. Professor do Curso Interdisciplinar em Educação do Campo: Ciências da Natureza da Universidade Federal da Fronteira Sul (UFFS), Campus Erechim/Rio Grande do Sul. Orcid: http://orcid.org/0000-0001-8220-7416. E-mail: moises.prsybyciem@uffs.edu.br

2 Pós-doutorado em Educação pela Universidade do Vale do Rio dos Sinos - UNISINOS, Professor do Mestrado Profissional em Educação e da Graduação da Universidade Federal Fronteira Sul - Campus Erechim/RS. Orcid: http://orcid.org/0000-000292833178.E-mail: almir.santos@uffs.edu.br
} 
Kaingang culture and three students are from a family farming context. For data collection/construction, a questionnaire, observation script and students' written production (didactic proposals) were used. The main results of the investigation point out the concern with the construction of a more politicized STL that stimulates a critical and conscious reading of the world and a greater social participation in decision-making processes on ScienceTechnology. This process can be achieved by overcoming the traditional conception of education, through discussions of Science-Technology-Society (STS) interrelations, training for social action and more committed, inclusive and democratic scientific education. These results contribute to stimulate the construction of an STL in this perspective and its relationship with culture and traditional indigenous knowledge in the initial training of teachers in Rural Education.

Keywords: Initial Teacher Training. Kaingang Indigenous Culture. STL. Rural Education. Natural Sciences.

\section{Introdução}

Os avanços científicos e tecnológicos vêm provocando várias mudanças na vida da população urbana e do campo nos contextos sociais, econômicos e ambientais. Essas mudanças baseadas no modelo atual de desenvolvimento econômico não trazem apenas benefícios, mas, também, geram incertezas, riscos e impactos negativos para a sociedade e para a natureza. Tais contradições, impactos e discursos hegemônicos sobre Ciência-Tecnologia (CT) fazem crescer a necessidade de uma maior participação social em processos de tomada de decisão sobre CT (CONCEIÇÃO; BAPTISTA; REIS, 2019).

Esse maior envolvimento das pessoas em processos decisórios demanda, no entanto, que a sociedade esteja alfabetizada científica e tecnologicamente, para, assim, poder realizar uma análise crítica e consciente dos obstáculos e das injustiças sociais, buscando o seu desvelamento e superação pela ação social (FREIRE, 2016). Assim, a formação de futuros professores nas Licenciaturas em Educação do Campo (LEdoC) na área de Ciências da Natureza deve estimular essa responsabilidade político-social e o compromisso com a mudança da realidade do campo de maneira justa e humana, o que pode ser alcançado pela Alfabetização Científico-Tecnológica (ACT) mais politizada.

Na LEdoC, acredita-se que uma ACT mais politizada consiste na compreensão e na superação de contradições, discursos e projetos hegemônicos sobre CT presentes na sociedade. Com essa compreensão, uma pessoa alfabetizada em CT pode ser capaz de realizar uma leitura e análise crítica da realidade, buscando a superação de obstáculos pela ação social individual e/ou coletiva no contexto comunitário e educacional (HODSON, 1998). A problematização das inter-relações CTS pode contribuir para esse processo (AULER; DELIZOICOV, 2001).

A Base Nacional Comum Curricular (BNCC), no ensino de Ciências, aponta como compromisso o desenvolvimento do letramento/alfabetização científica ${ }^{3}$ do estudante, com o propósito de desenvolver a capacidade de atuação no e sobre o mundo natural, social e tecnológico, visando à formação para a cidadania. (BRASIL, 2018). Porém, para formar um

\footnotetext{
${ }^{3}$ A BNCC em seu texto utiliza o termo letramento científico. Para Sasseron e Carvalho (2011), há uma polissemia em relação a esse termo. No contexto brasileiro, são encontrados, também, os termos: alfabetização científica e enculturação científica. Estas autoras apontam que mesmo com nomes diferentes, os objetivos são os mesmos, isso é, de promover as capacidades e as competências entre os estudantes, permitindo, assim a participação na tomada de decisão no cotidiano. Com base nesse estudo, optamos em utilizar o termo Alfabetização CientíficoTecnológica neste trabalho.
} 
estudante na educação básica, visando a atingir as competências, habilidades e conhecimentos essenciais previstos na BNCC nas áreas de Ciências da Natureza e Ciências da Natureza e suas Tecnologias, deve-se (re) pensar a formação inicial de professores em Ciências, buscando estimular práticas educativas mais investigativas, interdisciplinares e democráticas.

Neste estudo, os participantes são professores em formação inicial de uma LEdoC Ciências da Natureza. No referido curso de licenciatura e no componente curricular em específico, foco deste trabalho, a maioria dos acadêmicos são indígenas da cultura Kaingang. Para Caldart, Stedile e Daros (2015), as discussões nessa área do conhecimento são recentes e incipientes na Educação do Campo.

As principais implicações do ser professor do/no campo, conforme Prsybyciem, Santos e Sartori (2017), se referem à construção da identidade profissional, à responsabilidade políticosocial, como também à necessidade de compromisso com a transformação do meio social, visando torná-la mais justa, mais igualitária, inclusiva e humanizada.

Dessa forma, o objetivo deste trabalho é analisar as contribuições do desenvolvimento de um componente curricular denominado "Tópico I - Concepções de Ciência e Tecnologia" para a promoção de uma ACT e sua articulação com a cultura indígena Kaingang na formação inicial de professores em Educação do Campo - Ciências da Natureza de uma universidade federal brasileira.

\section{Compreendendo o contexto e os sujeitos da Licenciatura em Educação do Campo - Ciências da Natureza}

No contexto educacional brasileiro, as LEdoC vêm, ao longo dos últimos anos, ganhando notoriedade nacional e internacional, para a formação dos sujeitos do campo. É um espaço de constantes lutas pelos diversos movimentos, lideranças sociais e indígenas pelo direito e pela manutenção de uma educação pública de qualidade no/do Campo. Molina (2017) explicita que as experiências da oferta das LEdoC completaram dez anos em 2017 e que os trabalhos nelas desenvolvidos são marcados por um intenso processo de investigação e sistematização das concepções e práticas formativas.

Pertinente destacar que se está falando de um projeto para os povos camponeses, tendo uma estrutura pedagógica própria, constituída por sujeitos do campo, que, nos espaços da universidade, carregam uma bagagem cultural, vivências e experiências, que têm contribuído com as discussões científicas nos processos de ensino e de aprendizagem. Para Arroyo, Caldart e Molina (2004), os sujeitos do campo assumem, em seu projeto, a expectativa de uma educação pública de qualidade, sempre tendo presente o respeito às dinâmicas sociais e culturais, atendendo às necessidades e especificidades presentes nos processos pedagógicos.

O curso de LEdoC na área de Ciências da Natureza, neste estudo em específico, abarca um público das classes populares. $\mathrm{Na}$ atualidade, absorve um número elevado de acadêmicos oriundos dos povos indígenas da etnia Kaingang e Guarani, bem como de estudantes procedentes de movimentos sociais (por exemplo o Movimento dos Atingidos por Barragens $\mathrm{MAB}$ ) e da agricultura familiar, além de um público em geral interessado pela Educação do Campo. Esse cenário caracteriza uma diversidade cultural importante para a construção e a ressignificação da relação dialógica entre saberes populares/tradicionais e conhecimento científico.

De acordo com Prsybyciem, Santos e Sartori (2017), na Universidade Federal Fronteira Sul - Campus Erechim/RS, o curso da LEdoC apresenta um número elevado de acadêmicos 
indígenas da cultura Kaingang, que trazem para o espaço universitário a cultura, os costumes e as tradições que lhe são próprios. Nesse contexto, emergem situações problemas que são imbricadas com o conhecimento científico e tecnológico, constituindo-se como elementos importantes na preservação da cultura e na formação de professores. Uma temática que pode ser apontada como exemplo nesta pesquisa relaciona-se ao contexto da culinária indígena Kaingang.

Mineiro e Trichs (2018) explicitam que um dos elementos fundantes da cultura Kaingang é a alimentação. Na atualidade, o tema da alimentação tem sido recorrente nos espaços das rodas de conversas, ocasionando discussões e reflexões referentes à preservação da culinária tradicional e ao aumento considerável dos problemas nutricionais, principalmente em crianças, em decorrência da alimentação inapropriada, além de outras doenças, como diabetes e hipertensão arterial, nos adultos.

Para D'Angelis (2012), historicamente, os povos Kaingang tinham quatro fontes importantes de alimento, que eram provindos da coleta, da caça, da pesca e da agricultura. A coleta era de pinhão, palmito e frutas do mato (guabiroba, guamirim, jabuticaba, pitanga, dentre outros) que faziam parte da dieta Kaingang, conjuntamente com verduras do mato, como o "fuá" (Maria preta e/ou pimentinha preta) e o "kumin" (folha da mandioca brava), além de outras plantas importantes tanto para a medicina Kaingang quanto para o controle de pragas nas plantações. A caça e a pesca também faziam parte da alimentação Kaingang, e seu preparo, oriundo de sua cultura, era considerado fundamental na qualidade alimentar. Além desses alimentos, a agricultura garantia à cultura Kaingang a subsistência a partir da plantação de milho, feijão e morangas, os quais eram utilizados para fazer farinhas, bolos e bebidas. A culinária tem para o Kaingang um valor cultural inestimável.

O preparo dos alimentos geralmente é feito pelas pessoas mais idosas, que detêm os conhecimentos indispensáveis na culinária, visto que cada tipo de alimento tem seu modo de preparar e uma época certa para coleta. Nesse contexto, a universidade tem um papel central e importante, não somente para desenvolver os conhecimentos científicos, interligando a cultura e a culinária como uma possibilidade metodológica para o ensino e aprendizagem em Ciências, mas também no sentido de constituir um espaço de discussão e preservação da culinária indígena Kaingang, o que pode ser explorado nos componentes curriculares e nas práticas de Alternância ${ }^{4}$ ou de Estágio Curricular, fundamentais para a formação de futuros professores.

\section{Formação inicial de professores em Educação do Campo}

Os cursos de formação inicial de professores em Educação do Campo nas universidades públicas brasileiras surgiram a partir de reivindicações e mobilizações de vários movimentos, lideranças sociais e indígenas pelo direito ao acesso e à permanência dos sujeitos na educação

\footnotetext{
${ }^{4}$ A pedagogia da alternância é considerada um princípio metodológico que representa a construção de alternativas de escolarização dos povos do/no campo e se constitui no diálogo constante (relação dialética) entre o Tempo Comunidade (TC) e o Tempo Universidade (TU). Esses dois tempos são diferentes em relação a espaços, tempos, processos e produtos, mas são compreendidos de maneira integrada no processo de ensino e de aprendizagem. Esse processo consiste em outra maneira de fazer a escola do/no campo, de avaliação, da relação com os conteúdos, de mediação pedagógica e da relação professores e acadêmicos (ANTUNES-ROCHA; MARTINS, 2011). O TU como tempo, processos e espaço em que em que os acadêmicos-professores estarão na universidade, contemplando os conteúdos dos componentes/disciplinas curriculares do curso. Já o TC como tempo, espaço e processos em que os acadêmicos-professores estarão em seu local de origem, prioritariamente, desenvolvendo o trabalho pedagógico e as atividades de pesquisa nas escolas do/no campo e demais espaços educativos não escolares nas comunidades.
} 
superior. Muitos desses cursos são organizados por área de conhecimento, por exemplo, as Ciências da Natureza.

Conforme Caldart, Stedile e Daros (2015), as discussões na formação de professores para as escolas do campo, em específico na área de Ciências da Natureza, ainda são tímidas e recentes. Essa realidade, no entanto, precisa mudar, e o desenvolvimento da ciência e da tecnologia e as suas implicações para o contexto social precisam fazer parte das discussões na Educação do/no Campo (PRSYBYCIEM; SANTOS; SARTORI, 2017).

De acordo com Arroyo, Caldart e Molina (2004), os sujeitos do campo têm o direito a uma educação pública de qualidade e que respeite os contextos sociais e culturais, atendendo às especificidades e às necessidades que lhes são próprias. E, nessa direção, o projeto de educação para os povos do campo tem uma pedagogia própria, construída em colaboração com a comunidade e seus sujeitos.

Portanto, para atender a essas demandas, o projeto de Educação do Campo aponta a importância de formar professores capazes de compreender as contradições culturais, ideológicas, sociais, políticas, científicas, tecnológicas, produtivas, éticas e econômicas enfrentadas pelos sujeitos que vivem do/no campo. Essa compreensão e consciência crítica da realidade permitem desenvolver práticas educativas e organizacionais que preparem esses professores para enfrentar e desvelar contradições, discursos e projetos hegemônicos que afetam a sociedade (PRSYBYCIEM; SANTOS; SARTORI, 2017).

\section{Alfabetização científico-tecnológica no ensino de Ciências}

A ACT tem se mostrado, cada vez mais, como uma dimensão elementar para a sociedade no século XXI. Diversos pesquisadores e propostas curriculares defendem a ACT como objetivo central almejado na educação científica em todos os níveis de ensino (NRC, 1996; HODSON, 1998; AULER; DELIZOICOV, 2001; AAAS, 2001; KRASILCHIK; MARANDINO, 2007; SASSERON; CARVALHO, 2011; CHASSOT, 2017; BRASIL, 2018).

Nesse processo, as inter-relações CTS deveriam ser discutidas na escola, visando a avaliar as implicações sociais dos produtos, discursos e processos da CT e estimular a ação social para resolução das situações problemas na sociedade.

Para Auler e Delizoicov (2001), os objetivos que conduzem a ACT são vários, ou seja, podem ir de perspectivas tecnocráticas a mais democráticas. Na perspectiva tecnocrática, não há possibilidade de participação da sociedade (pessoas comuns - não especialistas) no processo de tomada de decisão sobre CT. As decisões geralmente são tomadas por especialistas que, muitas vezes, defendem apenas interesses econômicos e políticos. Os conceitos científicos são abordados de maneira acrítica, favorecendo uma leitura ingênua e mágica da realidade social (FREIRE, 2016).

Já a ACT, na perspectiva democrática, estimula uma maior participação social no processo de tomada de decisão, envolvendo uma negociação entre não especialistas e especialistas de maneira inclusiva e plural no processo decisório sobre CT. Os conceitos científicos são abordados de forma crítica, favorecendo, por conseguinte, uma leitura - também - crítica da realidade social (FREIRE, 2016).

Hodson (1988) defende uma Alfabetização Científica Crítica Universal muito mais politizada baseada em questões sociocientíficas, reconhecendo os contextos sociais, econômicos, culturais, políticos e ambientais. Esse processo estimula o desenvolvimento da tomada de decisão, a autonomia, a compreensão da natureza da Ciência, das inter-relações entre 
Ciência-Tecnologia-Sociedade (CTS) e dos procedimentos da investigação científica, favorecendo uma formação para ação social e uma cidadania responsável.

Assim, busca-se estimular uma formação de professores em educação do campo Ciências da Natureza mais politizada e comprometida com a sociedade. Para isso, há necessidade que os professores compreendam as contradições sociais, econômicas, políticas e culturais, enfrentadas pelos sujeitos que vivem do/no campo (PRSYBYCIEM; SANTOS; SARTORI, 2017).

Nesse cenário, também se revela importante destacar que esses professores em formação - indígenas e camponeses - mais do que ninguém, conhecem essas contradições, uma vez que seu cotidiano é marcado pela vivência de lutas por direitos, liberdade, educação, igualdade e justiça social. Isso significa dizer que se mostra relevante a universidade ouvir e aprender com os sujeitos do campo.

\section{Caminhos metodológicos}

A metodologia da pesquisa tem abordagem qualitativa, sendo delineada em relação aos procedimentos técnicos pelos pressupostos da pesquisa-ação. Para Carr e Kemmis (1986), a pesquisa-ação é entendida como uma forma de investigação autorreflexiva realizada pelos participantes envolvidos em situações sociais, buscando, assim, melhorar a racionalidade de suas práticas educativas, pela compreensão de suas próprias práticas e situações/contextos em que as práticas são realizadas.

Este estudo faz parte do projeto de pesquisa denominado "Concepções dos acadêmicos do curso Interdisciplinar em Educação do Campo: Ciências da Natureza sobre Ciência, Tecnologia e Sociedade". Esse projeto tem como objetivo identificar e analisar as concepções dos acadêmicos do referido curso sobre Ciência, Tecnologia e Sociedade, buscando relacionar com as suas características socioeconômicas e culturais. Tal processo favoreceu as discussões e reflexões do processo de formação no curso com os professores formadores, melhorando o processo de ensino e de aprendizagem, o que pode refletir na prática do futuro professor formado na UFFS, Campus Erechim, em Educação do Campo na área de Ciências da Natureza.

Participaram da pesquisa 23 acadêmicos, no segundo semestre de 2018, na disciplina "Tópico I - Concepções de Ciência e Tecnologia", componente curricular do primeiro semestre de um curso de graduação voltado à formação inicial de professores em Educação do Campo: Ciências da Natureza de uma universidade federal brasileira da região Sul do país. O grupo era composto por 14 acadêmicas e nove acadêmicos. Vinte participantes são autodeclarados indígenas, oriundos de terras indígenas da cultura Kaingang da região que engloba a Associação de Município do Alto Uruguai (AMAU/RS) de localização da Universidade Federal Fronteira Sul - Campus Erechim/RS, e três são oriundos de contextos da agricultura familiar.

Para obter as compreensões e a evolução conceitual dos acadêmicos, utilizou-se como instrumento um questionário com questões abertas e produção escrita (propostas didáticas). $\mathrm{O}$ questionário foi construído pelos pesquisadores e disponibilizado para os participantes no término da referida disciplina. Tal instrumento é composto por duas questões:

a) Por que é necessário alfabetizar os cidadãos em ciência e tecnologia no mundo contemporâneo?

b) Como alcançar uma alfabetização Científica e Tecnológica mais politizada no ensino de Ciências? 
O estudo foi desenvolvido, basicamente, em sete fases de investigação em um espiral de autorreflexão (Quadro 1). Assim, as fases consistem em: reconhecimento, planejamento, ação e observação e reflexão (primeiro ciclo). Após, procedeu-se ao replanejamento das ações, para uma nova implementação e observação, e à reflexão (segundo ciclo). Foram utilizados 12 encontros, 72 horas, no período integral, de setembro de 2018 a janeiro de 2019.

Quadro 1 - Fases de desenvolvimento da investigação orientado pelos pressupostos da pesquisa-ação

\begin{tabular}{|c|c|c|}
\hline Ciclos & Fases & Atividades realizadas \\
\hline \multirow{5}{*}{ Ciclo 1} & $\begin{array}{c}\text { Fase } 1 \\
\text { Reconhecimento }\end{array}$ & $\begin{array}{l}\text { - Diálogo entre professor da disciplina e acadêmicos para formação de um } \\
\text { grupo de coparticipantes para realização da investigação na referida } \\
\text { disciplina. } \\
\text { - Problematização sobre concepções iniciais dos acadêmicos. }\end{array}$ \\
\hline & $\begin{array}{c}\text { Fase 2 } \\
\text { Planejamento } \\
\text { colaborativo }\end{array}$ & - Planejamento colaborativo do plano de ação e atividades da disciplina. \\
\hline & $\begin{array}{l}\text { Fase } 3 \\
\text { Ação e observação }\end{array}$ & $\begin{array}{l}\text { - Implementação do plano de ação de ação } \\
\text { Leitura e reflexão dos textos da área de Ensino de Ciências: } \\
\text { - Learning and Teaching Science: Approach Personalized a Towards } \\
\text { (HODSON, 1998) - (Texto traduzido e disponibilizado pelo } \\
\text { professor para os acadêmicos); } \\
\text { - Uma análise de pressupostos teóricos da abordagem C-T-S (Ciência } \\
\text { - Tecnologia -Sociedade) no contexto da educação brasileira } \\
\text { (SANTOS; MORTIMER, 2000); } \\
\text { - Alfabetização científica: uma possibilidade para a inclusão social } \\
\text { (CHASSOT, 2003); } \\
\text { - Capítulo III - Educação em química: compromisso com a cidadania } \\
\text { (SANTOS; SCHNETZLER, 2010). }\end{array}$ \\
\hline & & $\begin{array}{l}\text { Orientação e construção de uma proposta didática na perspectiva CTS } \\
\text { seguindo os cinco momentos propostos por Santos e Mortimer (2000). }\end{array}$ \\
\hline & $\begin{array}{c}\text { Fase } 4 \\
\text { Reflexão }\end{array}$ & $\begin{array}{l}\text { - Realização de uma avaliação, análise e síntese coletiva sobre as propostas } \\
\text { didática. } \\
\text { - Avaliação e sistematização geral das contribuições das leituras realizadas } \\
\text { e articulação com as práticas educativas. }\end{array}$ \\
\hline \multirow{3}{*}{ Ciclo 2} & $\begin{array}{c}\text { Fase } 5 \\
\text { Replanejamento }\end{array}$ & $\begin{array}{l}\text { - Replanejamento das ações para reestruturação das propostas didáticas, com } \\
\text { base nas reflexões coletivas das sistematizações. }\end{array}$ \\
\hline & $\begin{array}{c}\text { Fase 6 } \\
\text { Novas ações e } \\
\text { observações }\end{array}$ & $\begin{array}{l}\text { - Reestruturação e apresentação de uma proposta didática na perspectiva } \\
\text { CTS, levando em consideração a cultura indígena Kaingang. }\end{array}$ \\
\hline & $\begin{array}{c}\text { Fase } 7 \\
\text { Novas Reflexões }\end{array}$ & $\begin{array}{l}\text { - Socialização e auto avaliação individual e coletiva da disciplina e das } \\
\text { propostas didáticas. }\end{array}$ \\
\hline
\end{tabular}

Fonte: Elaborado pelos autores, baseado em Kemmis; Mctaggart; Nixon (2014).

O processo de formação contemplou momentos que favoreceram a unidade entre saberes tradicionais indígenas e conhecimento científico, teoria-prática e ação-reflexão; 
problematização das percepções iniciais dos acadêmicos; leitura e reflexão de textos da literatura na área de Ensino de Ciências; orientação para construção e reestruturação das propostas didáticas; socialização das propostas didáticas e discussão sobre práticas educativas. Assim, o produto final foi uma proposta didática construída pelos acadêmicos.

Em relação à escolha dos problemas sociais para a construção das propostas didáticas, os acadêmicos tiveram autonomia para relacionar com seus interesses e com sua realidade na comunidade. Foram elaboradas cinco propostas didáticas em grupo, com as seguintes temáticas: agrotóxico nas aldeias indígenas; alcoolismo nas aldeias; culinária indígena Kaingang; tabagismo - uso de narguilé pelos jovens indígenas; e lixo nas terras indígenas. Neste trabalho, contudo, analisa-se tão somente a proposta didática culinária indígena Kaingang.

Para preservar a identidade dos participantes, os acadêmicos foram nominados como A1, A2, A3... A23. Foram garantidas a confidencialidade e a privacidade de todas as informações coletadas/construídas neste estudo, pois apenas os pesquisadores possuíam acesso aos dados. Na divulgação dos resultados, também foi garantido o anonimato dos participantes.

A análise dos dados foi realizada utilizando a análise de conteúdo. Essa metodologia é constituída de três fases: i) a pré-análise, ii) a exploração do material e iii) o tratamento dos dados, a inferência e a interpretação (BARDIN, 1977). Dessa análise emergiram, a posteriori, duas categorias: i) propostas didáticas e cultura indígena Kaingang: refletindo as práticas educativas; e ii) em busca de uma ACT mais politizada de futuros professores em Educação do Campo - Ciências da Natureza.

\section{Resultados e discussões}

6.1 Propostas didáticas e cultura indígena Kaingang: refletindo as práticas educativas

Para atingir o objetivo estabelecido, que consiste em analisar as contribuições do desenvolvimento de um componente curricular para promoção da ACT e articulação com a cultura indígena na formação de futuros professores em Educação do Campo - Ciências da Natureza, foi dada ênfase na análise da proposta didática culinária indígena Kaingang e nas respostas ao questionário aplicado no final da disciplina.

As propostas didáticas foram construídas na perspectiva CTS com base nos cinco momentos apontados por Santos e Mortimer (2000). As relações CTS favorecem o desenvolvimento de uma ACT (HODSON, 1998; SANTOS; SCHNETZLER, 2010). Todos os grupos buscaram relacionar com a cultura e as situações-problema encontradas no contexto indígena Kaingang para estruturar suas propostas. A seguir, apresenta-se a proposta didática sobre culinária nos cinco momentos.

a) Introdução de um problema social

Os acadêmicos organizados em grupo tiveram total autonomia intelectual e liberdade para escolher os problemas sociais relacionados ao seu contexto, interesse e realidade, estimulando a negociação, a tomada de decisão e o espírito democrático. Nessa atmosfera, foi desenvolvida a proposta didática "culinária indígena Kaingang", pensada para o nono ano do ensino fundamental.

Para esse grupo, os Kaingang tinham como fontes essenciais de alimento as práticas relacionadas à agricultura, à caça, à coleta e à pesca. Os registros apontaram para práticas como a coleta de pinhão, palmito, guabiroba e pitanga e para o cultivo de verduras como fuá (Maria preta e/ou pimentinha preta) e kumin (folha da mandioca brava), dentre outros que têm valor 
cultural imensurável para esse povo. Outro apontamento feito pelos acadêmicos como um problema social sentido pela comunidade indígena diz respeito ao fato de que, com o passar dos tempos, essa identidade cultural vem se perdendo, o que, muitas vezes, é motivado pelo modelo de desenvolvimento social e econômico atual, que promove mudanças nos hábitos alimentares, no meio ambiente (agrotóxicos, monocultura) e na saúde.

Para a problematização e a introdução desse problema social em sala de aula, os acadêmicos do grupo acreditam ser necessário resgatar esses saberes ligados à culinária. Assim, propõem um diálogo dos estudantes com os indígenas mais idosos da comunidade, que são considerados Kofás da cultura indígena Kaingang. Com esse diálogo, se pode resgatar quais os principais alimentos da cultura Kaingang, como identificar as plantas, os benefícios para a saúde em detrimento dos alimentos industrializados, os riscos do consumo inadequado e as formas de preparo.

Nos debates, de maneira colaborativa e participativa, os acadêmicos chegaram ao consenso de que a vivência e a problematização científica de maneira dialógica dos saberes tradicionais ligados à culinária podem contribuir para esse resgate cultural e para despertar o interesse dos estudantes em aprender Ciências.

b) Análise da tecnologia relacionada ao tema social

Para a análise da tecnologia em relação à problemática inicial, os acadêmicos utilizaram como exemplo o fuá e o kumin. O fuá pode ser preparado a partir da planta conhecida como Maria pretinha, com nome científico Solanum americanum. A planta e/ou as sementes não podem ser ingeridas de forma in natura, pois possuem componentes como os chamados alcaloides indólicos, que podem causar problemas de saúde (irritação gástrica, vômito e dor de cabeça). Assim, a tecnologia ligada ao processo de cozimento (fervura) para eliminar a toxidade e os micro-organismos presentes nas folhas (bactérias e fungos) e para proceder a mudanças químicas na estrutura da clorofila, dentre outros fenômenos, podem ser exploradas com os estudantes.

O kumin é preparado a partir da mandioca brava (Manihot esculenta Crantz), caracterizada por apresentar sabor amargo, o que se deve, principalmente, ao composto ácido cianídrico $(\mathrm{HCN})$, substância muito tóxica ingerida e/ou inalada, que pode ocasionar vários problemas de saúde. Para a produção do kumin, utiliza-se as folhas da mandioca brava, as quais têm alto valor nutritivo, composto por proteínas, carboidratos, vitaminas e minerais. O processo de cozimento das folhas (fenômenos e processos químicos e físicos) pode ser explorado em relação à tecnologia.

c) Estudo do conteúdo científico definido em função do tema social e da tecnologia introduzida

Conforme os acadêmicos, a proposta didática pode explorar vários conteúdos científicos, tais como: nutrientes presentes no fuá e no kumin; tabela periódica (manganês, magnésio, fósforo, ferro e boro); ponto de fusão e ponto de ebulição; nome científico; estrutura dos vegetais; separação de misturas homogêneas e heterogêneas; funções inorgânicas; ligações químicas; importância desses alimentos para a cultura Kaingang; distúrbios alimentares; indústria alimentícia e propaganda; saúde humana; Plantas Alimentícias Não Convencionais (PANC); dentre outros. 
d) Estudo da tecnologia correlata em função do conteúdo apresentado

Para esse momento, os acadêmicos acreditam ser possível produzir o fuá e o kumin com os estudantes, buscando uma relação dialógica entre a teoria-prática, ação-reflexão e saberes populares-conhecimento científico.

e) Discussão da questão social original

Após a produção dos alimentos, uma possibilidade apontada pelos acadêmicos é a realização de uma mostra cultural e científica, envolvendo toda comunidade (pais, estudantes, pessoas da comunidade, professores). Nesse momento, se pode voltar na questão social inicial e avaliar os avanços dos estudantes em relação ao processo.

Percebe-se, na análise da proposta didática, que essa maneira de abordar os conteúdos científicos rompe com a concepção de educação "tradicional", uma vez que parte de uma problemática social, procurando discutir as inter-relações CTS, mesmo que nessa proposta o foco seja a tecnologia. Essa abordagem favorece práticas educativas mais investigativas e interdisciplinares.

Nessa proposta, fica clara a possibilidade de uma relação dialógica entre os saberes tradicionais da cultura e culinária Kaingang com o conhecimento científico. Esse processo pode envolver toda comunidade escolar para discussão da identidade cultural Kaingang, abordando também os conhecimentos científicos e tecnológicos. Esse processo pode favorecer uma leitura crítica de mundo e uma maior participação social na tomada de decisão sobre CT (AULER; DELIZOICOV, 2001).

6.2 Em busca de uma ACT mais politizada de futuros professores em Educação do Campo Ciências da Natureza

Nas respostas ao questionamento "Por que é necessário alfabetizar os cidadãos em ciência e tecnologia no mundo contemporâneo?", percebe-se que $65 \%$ acreditam que a ACT é necessária para que os cidadãos possam realizar uma leitura crítica e consciente de mundo, e $35 \%$ dos acadêmicos afirmam que possibilita uma maior participação da sociedade no processo de tomada de decisão sobre CT, como representado na Tabela 1.

Tabela 1 - Necessidade de uma ACT dos cidadãos no mundo contemporâneo na compreensão dos acadêmicos

\begin{tabular}{|l|c|c|}
\hline \multicolumn{1}{|c|}{ Categorias } & \multicolumn{1}{c|}{ Acadêmicos } & Porcentagem \\
\hline Leitura crítica de mundo & $\begin{array}{c}\mathrm{A} 1, \mathrm{~A} 3, \mathrm{~A} 5, \mathrm{~A} 6, \mathrm{~A} 8, \mathrm{~A} 11, \mathrm{~A} 12, \mathrm{~A} 13, \mathrm{~A} 14, \\
\mathrm{~A} 16, \mathrm{~A} 17, \mathrm{~A} 19, \mathrm{~A} 20, \mathrm{~A} 22 \mathrm{e} \mathrm{A} 23 .\end{array}$ & $65 \%$ \\
\hline $\begin{array}{l}\text { Maior participação social na } \\
\text { tomada de decisão sobre CT }\end{array}$ & $\mathrm{A} 2, \mathrm{~A} 4, \mathrm{~A} 7, \mathrm{~A} 9, \mathrm{~A} 10, \mathrm{~A} 15, \mathrm{~A} 18 \mathrm{e} \mathrm{A} 21$. & $35 \%$ \\
\hline
\end{tabular}

Fonte: Elaborado pelos autores, com alicerce nas respostas dos participantes (2020).

A necessidade de desenvolver a capacidade de leitura crítica da realidade social e do mundo como justificativa de favorecer um ACT é observada nas respostas dos participantes A6, "[...] para as pessoas adquirirem conhecimentos essenciais para uma leitura de mundo e ação prática, podendo fazer críticas e conversar sobre CT com cientistas", e A14, “[...] para a ciência e tecnologia ser mais social e os cidadãos realizarem uma leitura crítica da realidade 
social, dando a possibilidade desses conhecimentos chegarem a todas as classes, não importando raça, cor e gênero". O acadêmico A23, por sua vez, destaca:

\begin{abstract}
Os sujeitos alfabetizados científica e tecnologicamente têm condições de interpretar os fenômenos naturais e sociais que acontecem na sociedade, ou seja, fazer uma leitura de mundo. Os meios de comunicação com informações científicas quase sempre distorcem amenizando os impactos negativos e valorizando apenas os benefícios. Um a pessoa alfabetizada, principalmente na realidade indígena não é facilmente manipulado pela elite que, muitas vezes, induzem e decidem os projetos científicos e tecnológicos.
\end{abstract}

Assim, percebe-se que a ACT fornece conhecimentos essenciais para uma leitura crítica de mundo e ação social, inclusive participando na tomada de decisão de maneira mais democrática e plural pela negociação com especialistas na produção de CT. A participante A14 aponta a necessidade de democratização da CT para todas as classes sociais, sem descriminação e exclusão social, o que reflete o pensamento de autores como Hodson (1998).

Muitos autores defendem uma leitura crítica da realidade social para o desvelamento dos obstáculos (por exemplo, discursos e projetos hegemônicos sobre CT) pela análise crítica, buscando a transformação do mundo para melhor (AULER; DELIZOICOV, 2001; CHASSOT, 2003; 2017; FREIRE, 2016).

Portanto, a leitura crítica da realidade e a tomada de decisão mais plural e democrática sobre CT devem ser estimuladas na formação inicial de professores na educação do campo. Esse processo permite capacitar os futuros professores para a realidade do campo, tornando-os capazes de compreender as diversas contradições enfrentadas pelos sujeitos que vivem do/no campo (PRSYBYCIEM; SANTOS; SARTORI, 2017).

O desenvolvimento científico e tecnológico e suas imbricações são cada vez mais inerentes à dinâmica social e cultural das pessoas no século XXI. Por esse motivo, a ACT dos estudantes em qualquer nível de ensino é um dos principais objetivos almejados no ensino de Ciências. Essa ACT deve (pelos menos deveria) estimular um maior envolvimento social sobre CT (HODSON, 1998; AULER; DELIZOICOV, 2001; KRASILCHIK; MARANDINO, 2007). Essa preocupação apareceu nas respostas de $35 \%$ dos participantes, como expresso pelas acadêmicas A2 e A10, respectivamente:

\footnotetext{
É importante alfabetizar porque a tomada de decisão pública pelo cidadão em uma democracia requer uma atitude cuidadosa, habilidades e conhecimentos relevantes, consciência e compromisso com valores e a capacidade de transformar atitudes, habilidades e valores em ação social no contexto do campo. Todos esses passos podem ser encorajados se uma perspectiva de tomada de decisão for incorporada ao processo educacional (resposta acadêmica A2).

Não se trata de mostrar as maravilhas da ciência, como a mídia faz, mas de facilitar a tomada de decisão com relação a saúde, meio ambiente e agricultura no meio em que vivemos, capacitar para entender um mundo cada vez mais tecnológicos e pensar com mais clareza nos desafios para os povos do campo (resposta acadêmica A10).
}

Nesse foco, verificamos, com base na visão das participantes, que a ACT se faz necessária para capacitar os cidadãos para participação e ação em processos decisórios sobre CT de maneira consciente e democrática em assuntos presentes no cotidiano dos sujeitos e 
comunidade do campo, tais como a saúde e o meio ambiente. Além disso, a acadêmica A10 aponta que devemos ultrapassar as visões midiáticas da ciência para pensar de maneira mais clara. Esses resultados vão ao encontro das reflexões de vários autores que discutem ACT (HODSON, 1998; AULER; DELIZOICOV, 2001).

Já para as respostas à questão "Como alcançar uma alfabetização Científica e Tecnológica mais politizada no ensino de Ciências?", a maioria (47,8 \%) acredita que uma maneira pode ser pela superação da concepção "tradicional" de educação no ensino de Ciências (Tabela 2). Todavia, apresentam formas diferentes de superar essa concepção, como observado na resposta de A22: "A ACT mais politizada, só pode ser alcançada pela superação da educação como transmissão de informação. As pessoas precisam entender que o desenvolvimento da CT é influenciado por interesses, valores e discursos. A compreensão das inter-relações CTS pode ajudar nisso". Os acadêmicos A9, A10, A12, A13 e A16 compartilham também dessas ideias.

Tabela 2 - Percepções dos acadêmicos de como alcançar uma ACT mais politizada no ensino de Ciências

\begin{tabular}{|l|c|c|}
\hline \multicolumn{1}{|c|}{ Categorias } & \multicolumn{1}{c|}{ Acadêmicos } & Porcentagem \\
\hline $\begin{array}{l}\text { Superação da concepção "tradicional” de } \\
\text { educação }\end{array}$ & $\begin{array}{c}\text { A2, A7, A9, A10, A12, A13, A16, } \\
\text { A17, A19, A22 e A23. }\end{array}$ & $47,8 \%$ \\
\hline $\begin{array}{l}\text { Educação mais comprometida com a sociedade } \\
\text { (democrática e inclusiva) }\end{array}$ & A4, A5, A6, A14, A20 e A21 & $26,1 \%$ \\
\hline $\begin{array}{l}\text { Formar para ação social no contexto educativo } \\
\text { e comunitário }\end{array}$ & A3, A8, A11 e A15 & $17,4 \%$ \\
\hline Não respondeu & A1 e A18 & $8,7 \%$ \\
\hline
\end{tabular}

Fonte: Elaborado pelos autores, com alicerce nas respostas dos participantes (2020).

Para os acadêmicos A2 e A19, uma forma de superar a concepção de ensino "tradicional" de Ciências seria a valorização dos conhecimentos iniciais dos estudantes (saberes tradicionais e/ou populares), fazendo assim o diálogo com o conhecimento científico sistematizado. Já o participante A17 acredita que um ensino interdisciplinar, baseado em investigação e que estimule a tomada de decisão e a autonomia do estudante, pode ser um caminho para esse processo. Em sua resposta, o acadêmico A23 aponta: "Ensinando e aprendendo a linguagem que está escrito o mundo natural de forma crítica. Renovar as formas tradicionais de fazer educação, respeitando a identidade dos sujeitos e suas diferentes culturas, crenças e valores".

Freire (2016) faz crítica à concepção bancária de educação, que, no ensino de ciências, se caracteriza pela transmissão acrítica, aproblemática e apolítica dos conhecimentos científicos e tecnológicos, com memorização de nomes e fórmulas para posterior repetição na avaliação. Essa educação não faz sentido para o estudante, pois não leva em consideração sua realidade concreta. Assim, para superar essa educação "tradicional", precisa-se estimular uma educação libertadora e problematizadora.

Conforme $26,1 \%$ os respondentes, para alcançar uma ACT mais politizada, se faz necessária a construção de uma educação mais comprometida com a sociedade, isso é, mais democrática e inclusiva, englobando todos os atores sociais, buscando atender a interesses, especificidades e necessidades de cada contexto, como relata A6: "Podemos alcançar um ensino de Ciências mais politizado quando pensarmos em uma educação que atenda às necessidades e interesses das pessoas e não do mercado. Quando a educação for democrática e inclusiva para 
todas as pessoas". Esse participante ainda cita Paulo Freire quando fala que "precisamos de uma educação libertadora em que as pessoas consigam se libertar pela análise crítica das coisas".

Já para 17,4\% dos participantes, uma maneira de alcançar uma ACT mais politizada é formar os estudantes para uma ação educacional e para uma ação social no contexto da comunidade. Isso pode ser observado na resposta de A15: "Pode ser atingida por meio de uma formação que aborde os aspectos históricos, sociais e culturais da construção da ciência e da tecnologia. Com uma educação humanizada e acessível a todos as pessoas e que inclua uma formação para a ação de forma responsável e justa". Outros 8,7\% não responderam à questão. Também, não apresentaram justificativa.

Essas ideias vão ao encontro das reflexões de Hodson (1998), que aponta para a necessidade de uma educação científica mais politizada e de uma ação social no contexto comunitário e educacional.

\section{Considerações finais}

Com a realização deste trabalho, entendemos a necessidade de estimular práticas educativas na formação inicial de professores do campo para promoção de uma ACT mais politizada, visando a um maior envolvimento social na tomada de decisão sobre CT e uma leitura crítica e consciente de mundo com objetivo de transformá-lo em um lugar melhor.

A formação de futuros professores de Ciências para escolas do campo deve proporcionar uma ACT mais politizada, visando contrapor as concepções tradicionais e tecnocráticas de tomada de decisão sobre CT que afetam a realidade da vida dos povos do campo e indígenas. Tal processo pode ser alcançado pela superação da concepção tradicional de educação, o que pode ser feito pela problematização das inter-relações CTS e de práticas educativas mais democráticas, inclusivas e interdisciplinares. Além disso, observa-se a necessidade de formar os cidadãos para o desenvolvimento de ações sociais e para a proposição de uma educação mais comprometida com a sociedade.

As inter-relações CTS favorecem o desenvolvimento de uma ACT dos futuros professores. Nesse processo, é possível refletir as práticas educativas dos acadêmicos, que, na sua maioria, são indígenas da cultura Kaingang. A abordagem CTS favorece a compreensão de contradições, discursos, projetos e processos hegemônicos sobre CT, o que se revela fundamental para uma análise crítica e consciente desses obstáculos para sua superação, principalmente no ensino de Ciências em sala de aula.

Esperamos, portanto, que os resultados deste estudo possam ampliar as discussões sobre a necessidade de promover uma ACT mais politizada na perspectiva democrática na formação inicial de professores de Ciências no contexto do campo.

\section{Referências}

AMERICAN ASSOCIATION FOR THE ADVANCEMENT OF SCIENCE (AAAS). Project 2061 Science for All Americans: Education for a changing future. Washington: AAAS, 2001. Disponível em: http://www.project2061.org/publications/sfaa/. Acesso em: 30 ago. 2020. 
ANTUNES-ROCHA, M. I.; MARTINS, M. F. A. Diálogo entre teoria e prática na Educação do Campo: Tempo Escola/Tempo Comunidade e alternância como princípio metodológico para organização dos tempos e espaços no curso de Licenciatura em Educação do Campo. In: MOLINA, M. C.; SÁ, L. M. (org.). Licenciaturas em educação do campo: registros e reflexões a partir das experiências -piloto (UFMG; UnB; UFBA e UFS). Belo Horizonte: Autêntica Editora, 2011, p. 213-228.

ARroyo, M. G.; CAldART, R. S.; MOLINA, M. C. (org.) Por uma educação do campo. Petrópolis, RJ: Vozes Editora, 2004. 216 p.

AULER, D.; DELIZOICOV, D. Alfabetização Científico-Tecnológica Para Quê?. Ensaio Pesquisa em Educação em Ciências, v. 3, n. 1, p. 122-134, 2001. Disponível em: http://www.scielo.br/scielo.php?pid=S1983-21172001000200122\&script=sci_arttext. Acesso em: 02 mar. 2020.

BARDIN, L. Análise de conteúdo. Lisboa: Edições 70, 1977. 225 p.

BRASIL. Ministério da Educação. Base Nacional Comum Curricular. Brasília: MEC, 2018. Disponível em: http://basenacionalcomum.mec.gov.br/. Acesso em 15 abr. 2020.

CALDART, R. S.; STEDILE, M. E.; DAROS, D. (org.) Caminhos para transformação da escola 2: agricultura camponesa, educação politécnica e escolas do campo. São Paulo, SP: Expressão Popular, 2015. 240 p.

CARR, W.; KEMMIS, S. Becoming Critical: Education, Knowledge and Action Research. London and Philadelphia: The Palmer Press, 1986.

CONCEIÇÃO, T.; BAPTISTA, M.; REIS, P. La contaminación de los recursos hídricos como punto de partida para el activismo socio-científico. Revista Eureka sobre Enseñanza y Divulgación de las Ciencias, v. 16, n. 1, p. 1502-1-1502-13, 2019. Disponível em: https://revistas.uca.es/index.php/eureka/article/view/4194. Acesso em: 02 mar. 2020.

CHASSOT, A. Alfabetização científica: uma possibilidade para a inclusão social. Revista Brasileira de Educação, s/v, n. 22, p. 89-100, 2003. Disponível em:

https://www.scielo.br/scielo.php?script=sci_arttext\&pid=S1413-24782003000100009. Acesso em: 14 jun. 2020.

CHASSOT, A. Alfabetização Científica: questões e desafios para a educação. 7. ed. Ijuí: Unijuí, 2017.

D’ANGELIS, W. R. A língua Kaingang. Portal Kaingang, 2012. Disponível em: http://www.portalkaingang.org/lgua_kaingang.pdf. Acesso em: 20 nov. 2020.

FREIRE, P. Pedagogia do oprimido. 62. ed. Rio de Janeiro: Paz e Terra, 2016.

HODSON, D. Teaching and Learning Science: Towards a Personalized Approach. Buckingham: Open University, 1998, 200 p. 
KEMMIS, S.; MCTAGGART, R.; NIXON, R. The Action Research Planner: Doing Critical Participatory Action Research. Singapore: Springer, 2014.

KRASILCHIK, M.; MARANDINO, M. Ensino de Ciências e cidadania. 2. ed. São Paulo: Moderna, 2007. 87 p.

NATIONAL RESEARCH COUNCIL (NRC). National science education standards. Washington, DC: National Academy of Sciences, 1996.

MINEIRO, S. K.; TRICHES, R. M. O papel do ambiente escolar na cultura alimentar Kaingang: o caso da Terra Indígena Rio das Cobras, PR. Interações, v. 19, n. 4, p. 757-771, 2018. Disponível em:https://www.scielo.br/scielo.php?script=sci_abstract\&pid=S151870122018000400757\&lng=en\&nrm=iso\&tlng=pt. Acesso em: 29 ago. 2020.

MOLINA, M. C. Contribuições das licenciaturas em educação do campo para as políticas de formação de educadores. Educ. Soc., Campinas, v. 38, n. 140, p. 587-609, 2017. Disponível em: https://www.scielo.br/scielo.php?pid=S0101-

$73302017000300587 \&$ script=sci_abstract\&tlng=pt. Acesso em: 29 ago. 2020.

PRSYBYCIEM, M. M.; SANTOS, A. P.; SARTORI, J. Formação de professores em Ciências da Natureza para escolas do/no campo na UFFS - Campus Erechim: perspectivas e desafios. Revista Brasileira de Educação do Campo, v. 2, n. 3, p. 941-964, 13 dez. 2017. Disponível em: https://sistemas.uft.edu.br/periodicos/index.php/campo/article/view/3924. Acesso em: 14 jun. 2020.

SANTOS, W. L. P.; MORTIMER, E. F. Uma análise de pressupostos teóricos da abordagem C-T-S (Ciência-Tecnologia-Sociedade) no contexto da educação brasileira. Revista Ensaio, v. 2, n. 2, p. 110-132, 2000. Disponível em:

https://www.scielo.br/scielo.php?script=sci_arttext\&pid=S1983-21172000000200110. Acesso em: 31 ago. 2020.

SANTOS, W. L. P.; SCHNETZLER, R. P. Educação em Química: compromisso com a cidadania. 4.ed. Ijuí: Unijuí, 2010.

SASSERON, L. H.; CARVALHO, A. M. P. Alfabetização científica: uma revisão bibliográfica. Investigações em Ensino de Ciências, v. 16, n. 1, p. 59-77, 2011. Disponível em: https://www.if.ufrgs.br/cref/ojs/index.php/ienci/article/view/246. Acesso em: 14 jun. 2020.

Recebido em agosto de 2020.

Aprovado em novembro de 2020. 